\title{
Apomorphine Hydrochloride
}

National Cancer Institute

\section{Source}

National Cancer Institute. Apomorphine Hydrochloride. NCI Thesaurus. Code C47400.

The hydrochloride salt form of apomorphine, a derivative of morphine and non-ergoline dopamine agonist with high selectivity for dopamine D2, D3, D4 and D5 receptors.

Apomorphine hydrochloride acts by stimulating dopamine receptors in the nigrostriatal system, hypothalamus, limbic system, pituitary gland, and blood vessels. This enhances motor function, suppresses prolactin release, and causes vasodilation and behavioral effects. Apomorphine hydrochloride is used in the treatment of Parkinson's disease and erectile dysfunction. In addition, apomorphine hydrochloride acts on the chemoreceptor trigger zone and is used as a central emetic in the treatment of drug overdose. 